\title{
ESTUDO DE POTENCIAIS INIBIDORES DA SUBTILISINA 1 DE PLASMODIUM FALCIPARUM POR DINÂMICA MOLECULAR
}

\author{
Thaís das Virgens Cardoso; Franco Henrique Andrade Leite ${ }^{2}$; David Bacelar \\ Costa Junior ${ }^{3}$; Janay Stefany Carneiro Araujo; Larissa de Mattos Oliveira ${ }^{5}$ \\ 1. Bolsista PIBIC/CNPq, Graduando em Farmácia, Universidade Estadual de Feira de Santana, e-mail: \\ Thais.v.cardoso@hotmail.com \\ 2. Orientador, Departamento de Saúde, Universidade Estadual de Feira de Santana, e-mail: \\ fhpharm@gmail.com \\ 3. Participante do projeto, Departamento de Saúde, Universidade Estadual de Feira de Santana, e-mail: \\ dbcjunior.uefs@gmail.com \\ 4. Participante do projeto, Departamento de Saúde, Universidade Estadual de Feira de Santana, e-mail: \\ janay@hotmail.com \\ 5. Participante do projeto, Departamento de Saúde, Universidade Estadual de Feira de Santana, e-mail \\ lare_oliveira@yahoo.com.br
}

PALAVRAS-CHAVE: Malária, subtilisina 1, dinâmica molecular.

\section{INTRODUÇÃO}

A malária é uma doença infecciosa caracterizada por episódios febris, causada pelo protozoário do gênero Plasmodium ssp. P. falciparum é o principal responsável pela forma mais grave da doença, a malária cerebral (BLACKMAN et al., 2012) que pode levar a morte. A terapia antimalárica atual é limitada, devido ao surgimento de cepas multirresistentes aos principais fármacos utilizados na terapêutica, como a mefloquina, cloroquina, artesunato, artemisinina, além do perfil de efeitos adversos graves (ex.: surtos psicóticos e convulsões) (GERMANO, 2005). Assim, torna-se necessária a identificação de potenciais moléculas bioativas para o desenvolvimento de fármacos mais potentes, seletivos e seguros através da exploração de alvos que são importantes para o ciclo de vida do parasita, como a Serino-protease subtilisina 1 do $P$. falciparum (PfSUB1; E.C 4LVN). Para alcançar esse objetivo, técnicas baseadas no conhecimento da estrutura do alvo macromolecular (ex.: acoplamento molecular) podem ser empregadas para a priorização de moléculas candidatas aos ensaios biológicos, juntamente com dinâmica molecular para a identificação do provável modo de ligação e caracterização das interações responsáveis pela estabilização da(s) molécula(s) no sítio de ligação. Dessa forma, o objetivo desse trabalho foi avaliar através de simulações de dinâmica molecular a estabilidade e a permanência das moléculas previamente priorizadas no plano anterior (Z174 e Z594; CNPq No 21, 2016-2017) no sitio ativo da PfSUB1.

\section{MATERIAL E MÉTODOS OU METODOLOGIA (ou equivalente) Preparo do receptor:}

A estrutura 3D da PfSUB1 (PDB: 4LVN) foi preparada com auxílio do módulo Biopolymer disponível na plataforma SYBYL®-X 2.0 (TRIPOS, 2012). Moléculas de água foram removidas e átomos de hidrogênio foram adicionados de forma a otimizar suas ligações de hidrogênio. O estado de protonação foi avaliado através do servidor $\mathrm{H}++$ (http://biophysics.cs.vt.edu) conforme análise do ambiente químico de cada resíduo e seu $\mathrm{pKa}$ e possíveis tautômeros dos resíduos presentes no sítio ativo foram 
ajustados manualmente, conforme disponível no módulo Biopolymer da plataforma SYBYL ${ }^{\circledR}-\mathrm{X} 2.0$.

\section{Parametrização das moléculas:}

Z174 e Z594 (> média mais duas vezes o desvio padrão) obtida na etapa de acoplamento molecular (CNPq No 21, 2016-2017) foram parametrizadas para as rotinas de dinâmica molecular. Para tal, as coordenadas 3D das poses melhores pontuadas foram submetidas ao servidor ATB 1.0 (MALDE et al., 2011, http://compbio.biosci.uq.edu.au/atb/) para a geração da sua topologia, usando o campo de força GROMOS96 53a6 (VAN DER SPOEL et al., 2005).

\section{Simulações de Dinâmica Molecular:}

As simulações de DM foram executadas no pacote GROMACS 5.1.2 (VAN DER SPOEL et al., 2005), com os seguintes parâmetros: campo de força GROMOS 53a6 e pressão de 1 bar. Posteriormente, ciclos de minimização energética (1000 ciclos de SteepestDescent (SD) e Gradiente Conjugado (GC), com critério de convergência de força de $1 \mathrm{Kcal} / \mathrm{mol} / \AA$ ), dinâmica de restrição (tempo = $1 \mathrm{~ns}$ ) e dinâmica produtiva de dados foram executados para a forma APO e complexo.

O sistema foi solvatado em caixa cúbica com modelo de água SPC/E(BERENDSEN; GRIGERA; STRAATSMA, 1987) com a proteína posicionada no centro da caixa com a distância $1,4 \mathrm{~nm}$ da borda da caixa. Contra-íons ( $\mathrm{Na}+$ ou Cl-) foram adicionados para neutralização dos sistemas. O método Lincs (HESS et al., 1997) foi aplicado na restrição de ligações covalentes de forma a permitir um passo de integração a cada 2 fentosegundos (fs). Os dados de dinâmica molecular foram obtidos no ensemble isotérmico-isobárico - NPT (número de partículas, temperatura e pressão constante), usando condições de contorno periódicas. As interações eletrostáticas e hidrofóbicas foram descritas pelo método PME (do inglês, ParticleMeshEwald) (DARDEN, YORK, PEDERSEN, 1993) com raio de corte igual a 0,9 nm.

A estabilidade do sistema será avaliada pelos parâmetros energéticos (energia total, cinética e potencial), valor do desvio médioquadrático (RMSD, do inglês Root Mean Square Deviation), disponível no pacote GROMACS 5.1.2.

\section{Seleção da estrutura representativa:}

A estrutura representativa de cada complexo durante a fase produtiva da DM foi calculada a partir do agrupamento das conformações semelhantes com auxílio do modulo g_cluster disponível no pacote GROMACS 5.1.2. Para tal foi utilizado o método de união GROMOS (DAURA; VAN GUNSTEREN; MARK, 1999) com valores de RMSD de 0,1 0,15 0,2 0,25 0,3e0,35nm, para a definição do ponto de corte. A seguir, a estrutura média no agrupamento mais representativo foi selecionado e utilizada para a avaliação das principais interações intermoleculares das moléculas com 
a PfSUB1 com o auxílio do programa PLIP (https://projects.biotec.tu-dresden.de/plipweb/plip/index).

\section{RESULTADOS E/OU DISCUSSÃO (ou Análise e discussão dos resultados)}

Em estudos anteriores (CNPq No 21, 2016-2017) Z174 e Z594 foram priorizadas por acoplamento molecular e portanto selecionadas para a etapa de DM. Essa rotina permitiu avaliar o efeito da presença de Z174 e Z594 no sítio de ligação para a estabilização da enzima. Assim foi realizada uma comparação dos gráficos de RMSD das simulações de DM da forma APO, APO- Z174 e APO- Z594 (Figura 1).

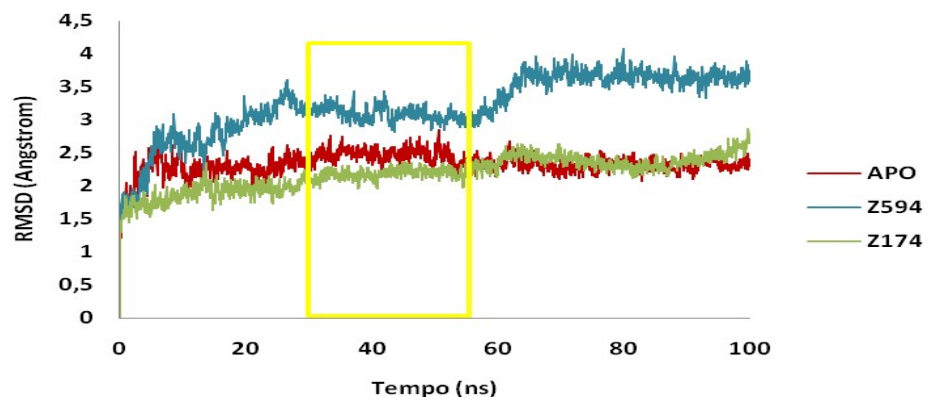

Figura 2. RMSD das estruturas submetidas a Dinâmica Molecular. Em verde, a estrutura APO, em vermelho, complexo APO-e ligante Z174, em azul, complexo APO-e ligante Z594, em destaque amarelo, o período estabilidade dos três sistemas.

A partir das análises dos RMSD verificou-se uma fase da DM que poderia ser considerada como período de maior estabilidade dos sistemas (30-50 ns). Nesse período a amplitude as variações do sistema foi menor que $2 \AA$ (SOARES,2009). Assim, essa análise permitiu determinar o período de maior estabilidade dos complexos para a obtenção das estruturas mais representativas da DM. Nesse momento foram avaliadas as interações responsáveis pela estabilidade dos complexos.

A estrutura representativa de Z174 apresentou duas ligações hidrofóbicas com a LEU461 e THR605 e uma ligação de hidrogênio com a SER492, que ocorre no ponto doador da Serina com o nitrogênio do ligante Z174 com receptor. Esse aminoácido do sitio ativo é fundamental na atividade da PfSUB1 que é uma Serino protease, sendo , (figura 4.), possivelmente responsável pela resposta observada na DM, complexo APOZ174 (figura 2).

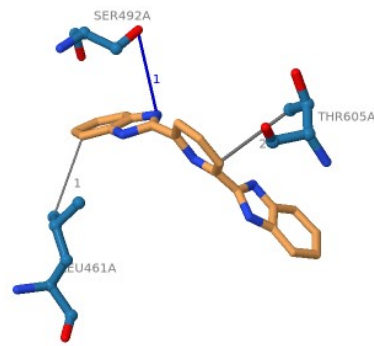

\begin{tabular}{l|l|l}
\hline \multicolumn{3}{c}{ Ligações hidrofóbicas } \\
\hline $\mathbf{N}^{0}$ & AA envolvido & DISTÂNCIA \\
\hline 1 & LEU/461A & 3.94 \\
\hline 2 & THR/605A & 3.98 \\
\hline \multicolumn{3}{|c}{ Ligação de hidrogênio } \\
\hline $\mathbf{N}^{0}$ & AA envolvido & $\begin{array}{l}\text { Distância } \\
\text { H-A/ D-A }\end{array}$ \\
\hline 1 & SER/492A & $3.34 / 3.80$ \\
\hline
\end{tabular}

Figura 2. Mapa das interações intermoleculares entre o ligante Z174 (laranja e azul) e o sitio da subtilisina 1 do Plasmodium falciparum. Representado em uma liga azul a ligação de hidrogênio e em cinza as ligações hidrofóbicas.

Fonte: Protein-Ligand Interaction Profiler. 
A estrutura representativa de Z594 apresentou quatro ligações hidrofóbicas com os aminoácidos, $\operatorname{ILE}(375,386)$, TYR411 e interações por empilhamento $\pi$ - $\pi$ paralelo entre os com o fenóis da TYR $(377,411)$ e o grupo fenol da do ligante Z594 (Figura 3.).

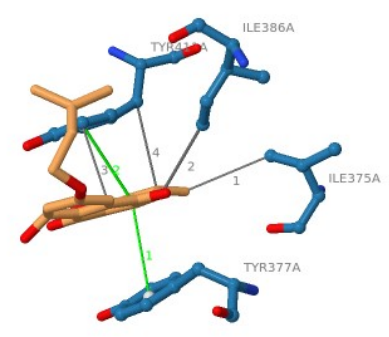

\begin{tabular}{c|l|l}
\hline \multicolumn{3}{|c}{ Ligações hidrofóbicas } \\
\hline $\mathbf{N}^{\mathbf{0}}$ & AA envolvido & Distância \\
\hline 1 & ILE/375A & $\mathbf{3 . 9 6}$ \\
\hline 2 & ILE/386A & $\mathbf{3 . 5 9}$ \\
\hline 3 & TYR/411A & 3.75 \\
\hline 4 & TYR/411A & $\mathbf{3 . 6 3}$ \\
\hline \multicolumn{3}{|c}{$\pi$-Stacking } \\
\hline $\mathbf{N}^{\mathbf{3}}$ & AA envolvido & Distância \\
\hline 1 & TYR377A & 4.11 \\
\hline
\end{tabular}

Figura 3. Mapa das interações intermoleculares entre o ligante Z594 e o sitio da Subtilisina 1 do de Plasmodium falciparum. Representado em linhas verdes as interações do tipo empilhamento $\pi$ e linhas cinza interações hidrofóbicas. Fonte: Protein-Ligand Interaction Profiler.

As interações com esses resíduos apesar de não serem ligações de hidrogênio podem ter contribuído para a permanência do ligante no sitio ativo, ainda que no período de tempo da simulação o ligante Z594 apresentou um patamar no RMSD maior que a simulação com a APO.

\section{CONSIDERAÇÕES FINAIS (ou Conclusão)}

A análise dos dados da simulação da Dinâmica Molecular com os ligantes Z174 e Z594, permitiu caracterizar o perfil de interações das moléculas promissoras para a inibição da subtilisina 1, observando seu acoplamento quando submetidas a condições mais similares ao meio biológico. Os dois ligantes permaneceram dentro sitio, contudo o ligante Z174 demonstrou-se mais estáveis dentro do sítio ativo durante o tempo de simulação no sistema. Assim, é promissora a continuação do estudo e avaliação do tanto do comportamento do ligante Z174, quanto para o ligante Z954.

\section{REFERÊNCIAS}

BLACKMAN, M. J. et al. 2011 Global IdentificationofMultipleSubstrates for Plasmodium falciparum SUB1, anEssentialMalarialProcessing Protease. Infection and Immunity, 79( 3): 1086-1097.

CHEMAXON. 2015, Marvin Sketch version 15.4.20: ChemAxon.

DARDEN, T; YORK, D; PEDERSEN, L.. 1993. ParticlemeshEwald: $N a N \cdot \log (N)$ method for Ewaldsums in large systems. 1. Chem. Phys. 98.

GERMANO, N., MENDONÇA, R. P., MURINELLO, A. 2005. Adequação dos fármacos antimaláricos na quimioprofi laxia e tratamento da malária em países não endêmicos. Medicina Interna.12(3).

SOUZA, R.O.S. 2009. Dinâmica Molecular de proteinas: estabilidade e renaturação térmica. Ribeirão preto::86

VAN DER SPOEL, D. ET AL. 2005. GROMACS: Fast, flexible, and free.

JournalofComputationalChemistry. 26 (16):1701-1718. 